\title{
Locally Invasive Diffuse Iris Ring Melanoma Presenting as Unilateral Severe Glaucoma: Case Report and Review of Molecular Genetics
}

\author{
Mina M. Naguib ${ }^{a}$ Patricia Chévez-Barrios ${ }^{a, b}, c, d, e$ Silvia Orengo-Nania ${ }^{a}$ \\ Amy C. Schefler ${ }^{c, d}$ e \\ aDepartment of Ophthalmology, Baylor College of Medicine, Houston, TX, USA; \\ bepartment of Pathology and Genomic Medicine, Houston Methodist Hospital, Houston, \\ TX, USA; 'Department of Ophthalmology, Blanton Eye Institute, Houston Methodist \\ Hospital, Houston, TX, USA; ${ }^{d}$ Retina Consultants of Houston, Houston, TX, USA; eWeill \\ Cornell Medical College, Houston Methodist Hospital, Houston, TX, USA
}

\section{Keywords}

Diffuse iris ring melanoma - Molecular genetics - Neovascular glaucoma - Gene expression assay

\begin{abstract}
We report the clinical history and histopathological findings in a case of diffuse iris ring melanoma (DIM) and review the most recent literature and modern molecular genetics of this entity. An 85-year-old Hispanic man presented with severe unilateral glaucoma, managed at an outside institution for 2 years prior to presentation. Diffuse pigmentation was noted in the angle, on the intraocular lens implant, and in the vitreous without clear demonstration of a mass on ultrasound biomicroscopy. Workup for metastatic cutaneous melanoma was negative. Histopathological examination of the enucleated eye revealed a mixed cell type iris ring melanoma with diffuse intraocular involvement. Gene expression profiling (GEP) revealed a class 2 molecular signature indicating a very high risk for metastases. Unilateral glaucoma presenting with marked pigmentation in the anterior chamber angle should be managed as melanoma until proven otherwise. Iris ring melanomas are known to have an aggressive clinical course, and recent molecular analyses indicate that they are likely primarily GEP class 2 with a very poor prognosis, similar to the majority of ciliary body melanomas.
\end{abstract}




\section{Introduction}

Iris melanomas are the most common primary malignancy of the iris [1, 2] but comprise only $3-5 \%$ of all uveal melanomas $[3,4]$. Depending on growth pattern, this entity can be divided into two general categories. About $90 \%$ have distinct margins and are classified as circumscribed. The remaining $10 \%$ are categorized as diffuse and display a growth pattern that is flat, infiltrative, and poorly defined, contiguous, or multifocal [5]. Because of this occult growth pattern, diffuse iris melanomas (DIMs) are difficult to recognize and diagnosis is often significantly delayed [6]. Additionally, characteristic involvement of the anterior chamber angle frequently leads to a severe glaucoma which is often subsequently treated without knowledge of the underlying mechanism. In addition to its diagnostic challenges, DIMs display more aggressive features having a higher propensity for epithelioid cell differentiation and a higher metastatic rate as compared to the circumscribed subtype $[1,5,7]$. This characteristic tumor behavior is likely related to underlying differences in molecular genetics which have been elucidated in recent years in uveal melanoma $[8,9]$ but have yet to be well described in DIMs.

\section{Case Report}

An 85-year-old Hispanic man presented to our glaucoma service for a second opinion after 2 years of treatment by an outside glaucoma and retina specialist for presumed uncontrolled neovascular glaucoma of the left eye. Despite the use of maximum topical medical therapy and intravitreal anti-VEGF injections, the glaucoma remained uncontrolled.

Vision in the left eye was no light perception with an intraocular pressure of $54 \mathrm{~mm} \mathrm{Hg}$. There was $3+$ conjunctival injection with scleral pigmentation noted at 9 o'clock, diffuse microcystic corneal edema, 1+ anterior chamber cell, and a fixed and dilated pupil with ectropion uveae between 2 and 4 o'clock and dark iris pigmentation from 2 to 9 o'clock.

Fig. 1. Fundus photograph of the left eye demonstrating poor view to the retina from loose, floating pigmented cells in the vitreous.

Fig. 2. Ultrasound biomicroscopy demonstrating irregular iris thickening but no definite focal mass.
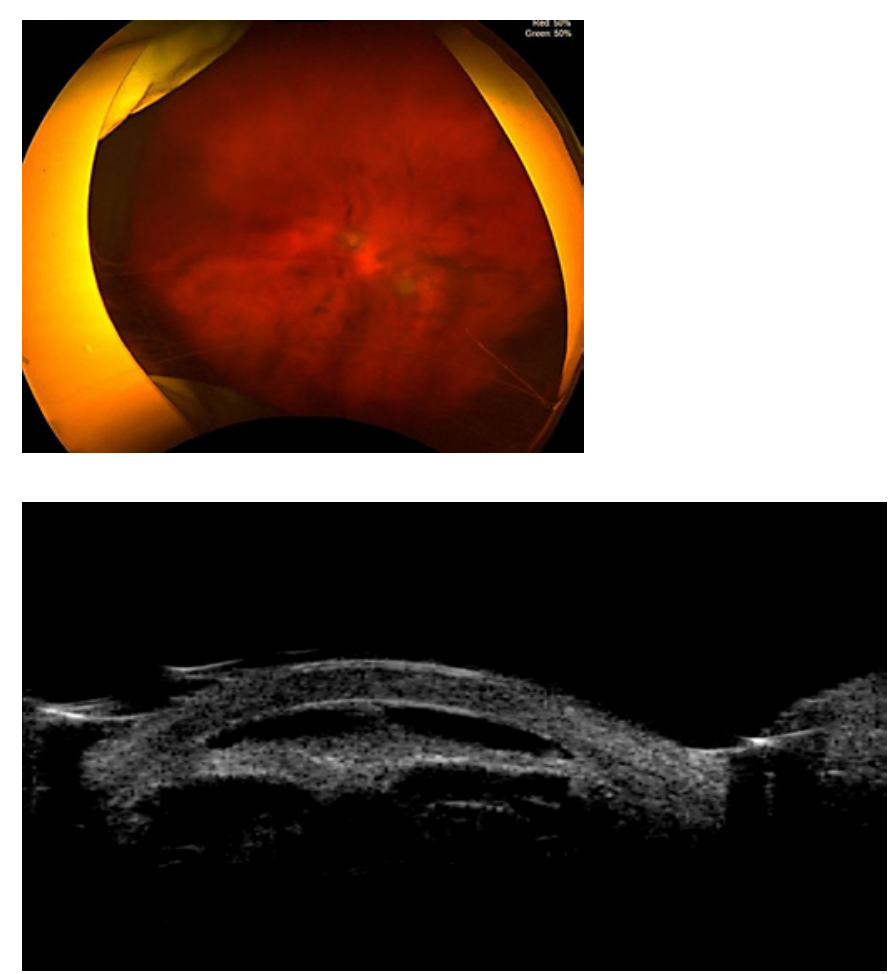


\section{Case Reports in Oncology}

\begin{tabular}{l|l}
\hline Case Rep Oncol 2021;14:403-410 \\
\hline DOI: 10.1159/000512012 & $\begin{array}{l}\text { ○ 2021 The Author(s). Published by S. Karger AG, Basel } \\
\text { www.karger.com/cro }\end{array}$ \\
\hline
\end{tabular}

Naguib et al.: Diffuse Iris Melanoma Presenting as Unilateral Glaucoma

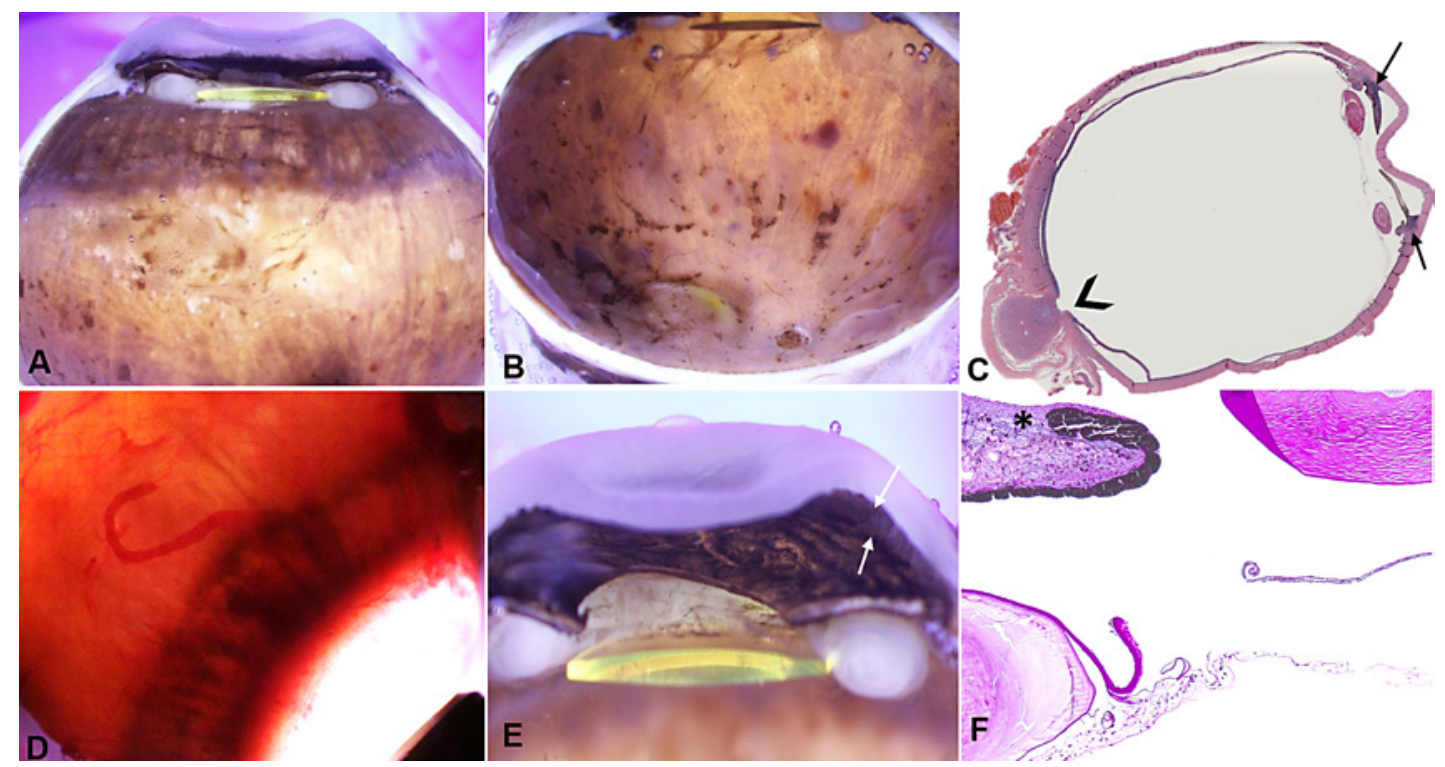

Fig. 3. Enucleated eye: pathology findings. A At the top of the macroscopic photograph, the anterior chamber angle is hyperpigmented, without a mass. There is a cross-section of the secondary Soemmerring's type cataract associated with the intraocular lens in the posterior chamber. The ciliary body and peripheral retina show brown deposits but no mass. B The posterior pole shows the dusty appearance of the vitreous and inner retina. The macula (yellow) and the optic nerve are focally covered by the pigmented deposits. C Digital scan of a section of the eye without mass formation but with hyperpigmentation of the angle (arrows). Note the excavated optic nerve head (arrowhead) resulting from glaucoma (hematoxylin and eosin stain). D Transillumination at the time of grossing of the eye shows no defined mass but irregular hyperpigmentation of the ciliary body. Light shown through cornea. E Detail of the anterior chamber shows hyperpigmentation of the trabeculum and anterior chamber angle (in between arrows). The iris surface is flat and with irregular pigmentation. The pupil is irregular with ectropion uvea better seen on the left side of this picture, and there is an irregularly pigmented membrane on the surface of the lens. F Histologic section of the same area seen in $\mathbf{E}$ demonstrating the ectropion uvea of the iris with a neoplastic membrane $\left(^{*}\right)$ pulling the pigmented epithelium. The pigmented membrane is composed of melanoma cells seen here forming a scroll. At the bottom left, the lens capsule and secondary cataract are seen partially surrounded by single melanoma cells. Periodic acid-Schiff stain, $\times 2$ original magnification.

Pigment was seen on the anterior surface of the posterior chamber intraocular lens, and the vitreous was filled with loose, floating, pigmented cells (Fig. 1). Gonioscopy of the left eye revealed dense pigment $360^{\circ}$ in the angle, while the right eye gonioscopy examination was normal. The patient was referred to ocular oncology, where he underwent a B-scan and ultrasound biomicroscopy, which revealed some irregular iris thickening at 3 o'clock but no definite focal mass (Fig. 2). Because of the marked degree of pigment deposition throughout the eye and a failure to identify a clear intraocular neoplasm, the patient was sent for full body dermatologic evaluation and whole-body PET scan to exclude metastatic cutaneous melanoma. No evidence of cutaneous melanoma was found, and the patient was diagnosed clinically with likely DIM. Enucleation was recommended.

The enucleated eye was filled with pigment in the anterior and posterior segments (Fig. 3). Histopathological examination showed a diffuse iris ring-type melanoma involving the ciliary body, iris root, and approximately $75 \%$ of the anterior chamber angle structures (Fig. 3C). On transillumination at the time of fresh tumor retrieval, there was no well-defined mass. There were irregular shadows in the anterior portion of the ciliary body and iris root 


\section{Case Reports in Oncology}

\begin{tabular}{l|l}
\hline Case Rep Oncol 2021;14:403-410 \\
\hline DOI: 10.1159/000512012 & $\begin{array}{l}\text { @ 2021 The Author(s). Published by S. Karger AG, Basel } \\
\text { www.karger.com/cro }\end{array}$ \\
\hline
\end{tabular}

Naguib et al.: Diffuse Iris Melanoma Presenting as Unilateral Glaucoma
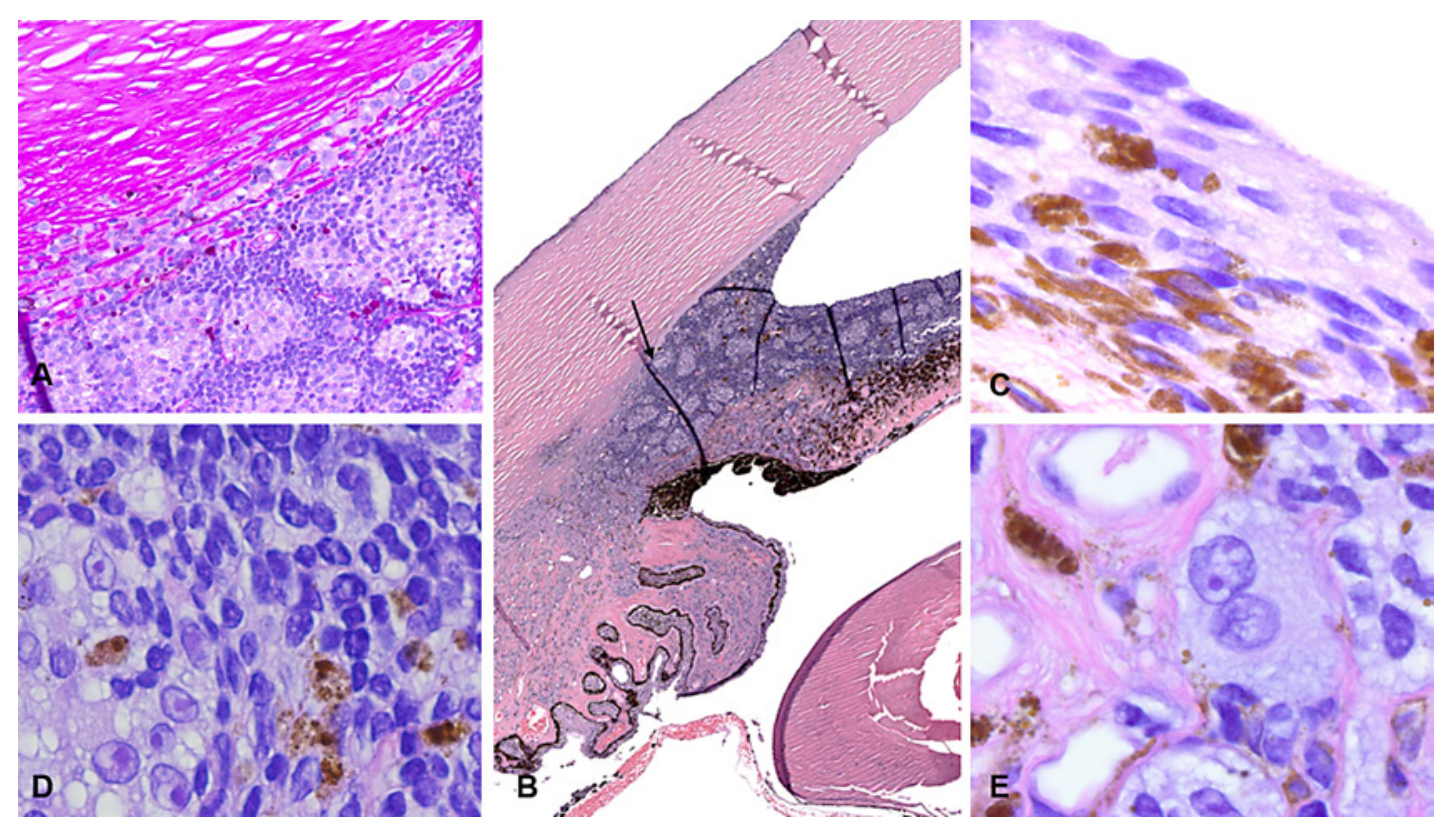

Fig. 4. Melanoma tumor cells in the angle and structures of the anterior chamber. A Nests of epithelioid (clear large cells) and spindle B-type cells (smaller blue cells) invade the trabecular meshwork at the angle. Please note the dissection of the tumor cells into the trabecular meshwork in the middle of the photograph. Periodic acid-Schiff, $\times 10$ original magnification. B Overview of the anterior segment with the tumor infiltrating the angle and the iris surface. Note the end of Descemet's membrane (arrow) and the tumor filling the angle. Hematoxylin and eosin, $\times 2$ original magnification. C Closeup of the tumor cells lining the anterior surface of the iris near the ectropion uvea. There are spindle cells with both types A and B melanoma cells partially pigmented. Hematoxylin and eosin, $\times 100$ original magnification. D Closeup of the tumor cells at the angle with large epithelioid cells with clear cytoplasm and prominent nucleoli alternating with spindle cells. Hematoxylin and eosin, $\times 100$ original magnification. E Binucleated epithelioid cells infiltrate deep in the stroma of the iris at the root of the iris. Hematoxylin and eosin, $\times 100$ original magnification.

(Fig. 3D). The thin pigmented membrane over the intraocular lens was composed by pure melanoma cells and the trabecular meshwork was hyperpigmented (Fig. 3E, F). The tumor was composed mainly of spindle B-type cells extending in a sheath-like pattern over the iris with epithelioid-type cells seen at the tumor margins forming nests and invading the trabecular meshwork, Schlemm's canal, and focally into aqueous veins (Fig. 4). The vitreous had tumor seeds of pigmented melanoma cells that lined the inner limiting membrane of the retina (Fig. 5) and the inner limiting membrane of the optic nerve. The optic nerve was markedly cupped and atrophic with Schnabel's degeneration with focal invasion by a few single epithelioid melanoma cells into the nerve head and lamina cribrosa (Fig. 5). Gene expression profiling (GEP) revealed a class 2, Prame-negative molecular signature. The patient continues to undergo routine metastatic surveillance and currently, at 17 months' follow-up, has no radiographic evidence of metastatic uveal melanoma.

\section{Discussion}

DIMs are notoriously difficult to diagnose and are frequently treated as severe unilateral glaucomas without knowledge of the underlying malignant process. One study of 24 cases identified an average delay to diagnosis of 30 months and over $50 \%$ of such cases undergoing 


\section{Case Reports in Oncology}

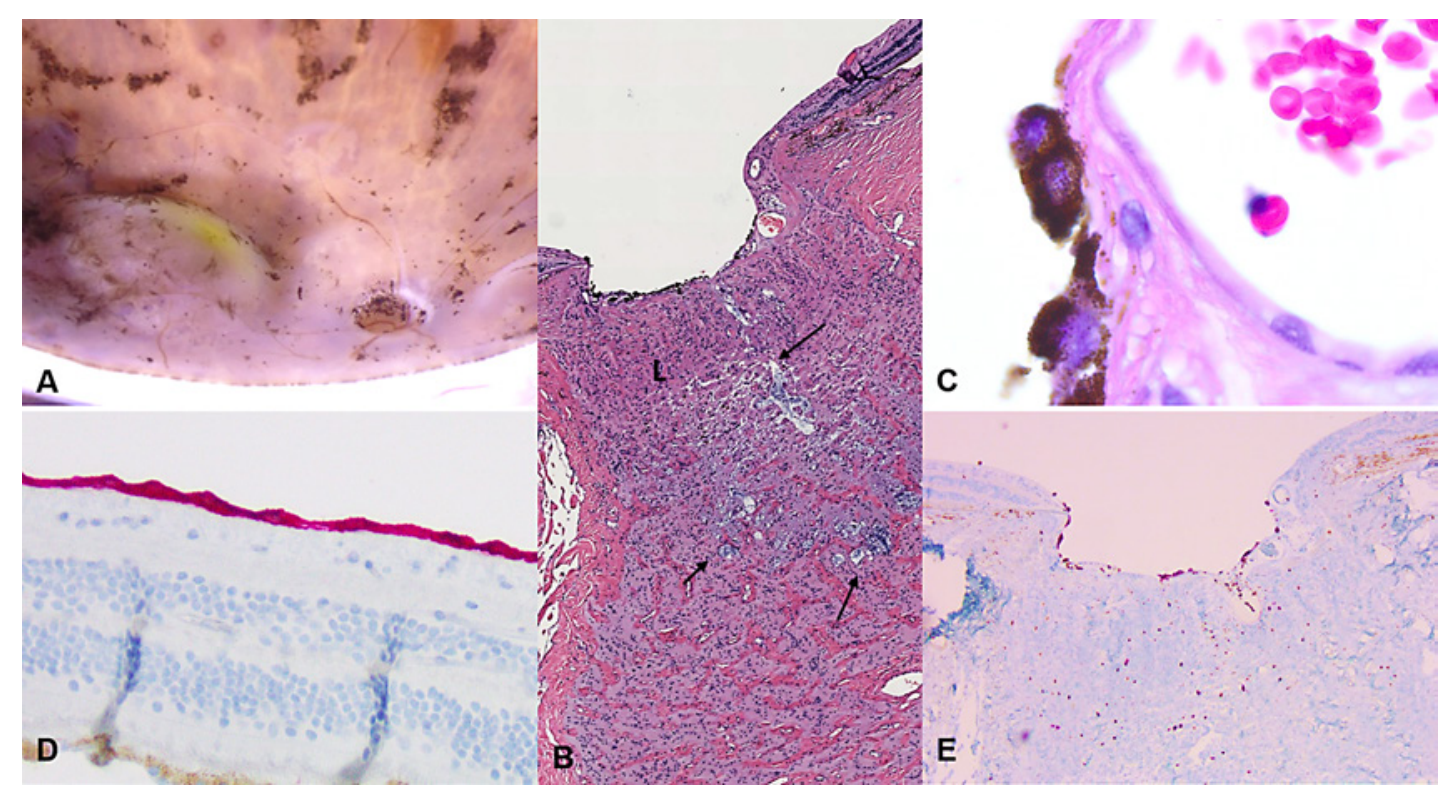

Fig. 5. Findings of the posterior pole of the eye. A Macroscopic photograph of the retina, macula, and optic nerve head. Notice the pigmented deposits, some stellate shaped, on the surface of the retina and on the surface of the markedly excavated atrophic optic nerve head. B Histologic representative section of the excavated optic nerve head with pigmented cells layering the surface and invading the lamina cribrosa (L). Postlaminar optic nerve shows basophilic (blue) cystic cavities (arrows) of Schnabel's degeneration. Hematoxylin and eosin, $\times 2$ original magnification. C High-power view of the optic nerve head surface over the central vein with epithelioid pigmented melanoma cells. Hematoxylin and eosin, $\times 100$ original magnification. D Retina with melanoma cells on the inner limiting membrane highlighted by HMB45 immunostain. Immunohistochemistry, HMB45 antibody; AEC red chromogen; $\times 10$ original magnification. E Optic nerve head with melanoma cells highlighted by HMB45 immunostain in red layering the inner surface and infiltrating in single cells the optic nerve. Immunohistochemistry, HMB45 antibody; AEC red chromogen; $\times 4$ original magnification.

prior medical or surgical treatment for glaucoma [6]. This underscores the vital importance of excluding an occult melanoma when evaluating and treating unilateral glaucoma with marked pigmentation relative to the fellow eye. Furthermore, neovascularization of the iris can occur in these cases, leading to a presumed diagnosis of neovascular glaucoma from retinal ischemia and the use of anti-VEGF therapy. Such injections may lead to extraocular seeding of melanoma cells from direct iatrogenic extension at the injection site.

Iris melanomas overall have a much lower 5-year risk of metastatic disease (4\%) than choroidal melanomas or ciliary body melanomas [10]. A recent study by Scholz et al. [11] found that $42 \%$ of iris melanoma tumor samples contained EIF1AX mutations, which has been shown in uveal melanoma to associate with a class $1 \mathrm{GEP}$ and a low rate of metastatic susceptibility. The DIM subtype, however, has a much higher 5-year rate of metastatic disease (13\% at 6 years) [6]. The genetic basis behind this propensity for more aggressive behavior among DIMs has not been described. This case is the first to report the GEP and Prame status of a DIM, to our knowledge, and provides a molecular basis for the previously published clinical observation of high metastatic propensity among these lesions. Among uveal melanomas of the ciliary body and choroid, the presence of a GEP class 2 signature is typically characterized by somatic mutations in BAP1 and a very high rate of metastatic disease within 5 years. GEP class 2 signatures are more common in lesions arising from the ciliary body rather than the choroid [12], and DIMs have often been shown histopathologically to involve the ciliary body, raising the question as to whether they are

\section{Karger'}


Table 1. Review of diffuse iris melanomas in the literature

\begin{tabular}{|c|c|c|c|c|}
\hline Authors [ref.], year & $\begin{array}{l}\text { Number } \\
\text { of cases }\end{array}$ & $\begin{array}{l}\text { Percent of cases } \\
\text { requiring enucleation }\end{array}$ & $\begin{array}{l}\text { Average } \\
\text { nfollow-up, } \\
\text { years }\end{array}$ & $\begin{array}{l}\text { Mean intraocular } \\
\text { pressure at } \\
\text { presentation, mm Hg }\end{array}$ \\
\hline \multicolumn{5}{|l|}{ Case series } \\
\hline Jakobiec and Silbert [1], 1981 & 4 & not reported & 11 (mean) & not reported \\
\hline Demirci et al. [6], 2002 & 25 & $88 \%(22 / 25)$ & 6.5 (mean) & 36 \\
\hline Konstantinidis et al. [14], 2013 & 12 & $0 \%$ & 3.5 (median) & not reported \\
\hline Willerding et al. [15], 2015 & 54 & $5.5 \%(3 / 54)$ & 5 (mean) & 21 \\
\hline Leblanc et al. [16], 2019 & 14 & $64 \%(9 / 14)$ & 4.6 (median) & not reported \\
\hline Finger et al. [17], 2020 & 11 & $0 \%$ & 4.9 (mean) & 18 (median) \\
\hline \multicolumn{5}{|l|}{ Case reports } \\
\hline Brown et al. [18], review of cases before 1990 & $\begin{array}{l}1 \text { (reviewed } 37 \\
\text { prior) }\end{array}$ & $0 \%$ & 2.5 & 35 \\
\hline $\begin{array}{l}\text { Single case reports [19-32] since } 1990 \text { and those } \\
\text { before not cited in Brown et al. }\end{array}$ & 14 & & & \\
\hline
\end{tabular}

in fact primarily of ciliary origin. Table 1 provides a review of all DIMs reported in the literature. In our case, the tumor also invaded the surface of the retina and the optic nerve with a neuroinvasive behavior probably associated with the class 2-type tumor. The cells that invaded the trabecular meshwork and the optic nerve had an epithelioid morphology also associated with high risk for metastasis and to BAP1 mutations [13].

In conclusion, the current case demonstrates the need to consider iris ring melanoma in cases of unilateral glaucoma associated with marked pigmentation in the angle. DIMs are a rare subtype of iris melanomas which carry a genomic signature and metastatic risk profile more similar to ciliary body melanomas than iris melanomas. In patients who have had a clinical diagnosis of a DIM and have not undergone testing for GEP, clinicians should consider surveillance for metastatic disease on a schedule similar to what they would pursue with a patient with a class 2 signature, as the majority of these patients are likely to have aggressive disease. Further studies are needed to determine why certain melanocytic lesions of the ciliary body develop in a diffusely infiltrative fashion and others in a more solid configuration, and why the molecular genetics vary by cell of origin within the uveal tract.

\section{Statement of Ethics}

Our study was exempt from IRB approval because our institution does not require it in reports of only 1 subject. Written informed consent was obtained from the patient for publication of this case report and any accompanying images.

\section{Conflict of Interest Statement}

The authors declare no conflicts of interest related to this case.

\section{Funding Sources}

No research funding sources were used in the presentation of this article.

\section{Karger'}


Naguib et al.: Diffuse Iris Melanoma Presenting as Unilateral Glaucoma

\section{Author Contributions}

Substantial contributions to the conception or design of the work; or the acquisition, analysis, or interpretation of data for the work: M.M.N., P.C.-B., S.O.-N., and A.C.S.

Drafting the work or revising it critically for important intellectual content: M.M.N., P.C.-B., S.O.-N., and A.C.S.

Final approval of the version to be published: M.M.N., P.C.-B., S.O.-N., and A.C.S.

Agreement to be accountable for all aspects of the work in ensuring that questions related to the accuracy or integrity of any part of the work are appropriately investigated and resolved: M.M.N., P.C.-B., S.O.-N., and A.C.S.

\section{References}

1 Jakobiec FA, Silbert G. Are most iris "melanomas" really nevi? A clinicopathologic study of 189 lesions. Arch Ophthalmol. 1981;99(12):2117-32.

2 Duke JR, Dunn SN. Primary tumors of the irs. AMA Arch Ophthalmol. 1958;59(2):204-14.

3 McLaughlin CC, Wu XC, Jemal A, Martin HJ, Roche LM, Chen VW. Incidence of noncutaneous melanomas in the U.S. Cancer. 2005;103(5):1000-7.

4 Krantz BA, Dave N, Komatsubara KM, Marr BP, Carvajal RD. Uveal melanoma: epidemiology, etiology, and treatment of primary disease. Clin Ophthalmol. 2017;11:279-89.

5 Ashton N. Primary tumours of the iris. Br J Ophthalmol. 1964;48(12):650-68.

6 Demirci H, Shields CL, Shields JA, Eagle RC, Honavar SG. Diffuse iris melanoma: a report of 25 cases. Ophthalmology. 2002;109(8):1553-60.

7 Shields CL, Shields JA, Materin M, Gershenbaum E, Singh AD, Smith A. Iris melanoma: risk factors for metastasis in 169 consecutive patients. Ophthalmology. 2001;108(1):172-8.

8 Onken MD, Worley LA, Char DH, Augsburger JJ, Correa ZM, Nudleman E, et al. Collaborative Ocular Oncology Group report number 1: prospective validation of a multi-gene prognostic assay in uveal melanoma. Ophthalmology. 2012;119(8):1596-603.

9 Berry DE, Schefler AC, Seider MI, Materin M, Stinnett S, Mruthyunjaya P, et al. Correlation of gene expression profile status and American Joint Commission on Cancer stage in uveal melanoma. Retina. 2020;40(2):214224.

10 Shields CL, Furuta M, Thangappan A, Nagori S, Mashayekhi A, Lally DR, et al. Metastasis of uveal melanoma millimeter-by-millimeter in 8033 consecutive eyes. Arch Ophthalmol. 2009;127(8):989-98.

11 Scholz SL, Möller I, Reis H, Süßkind D, van de Nes JAP, Leonardelli S, et al. Frequent GNAQ, GNA11, and EIF1AX mutations in iris melanoma. Invest Ophthalmol Vis Sci. 2017;58(9):3464-70.

12 Corrêa ZM, Augsburger JJ. Independent prognostic significance of gene expression profile class and largest basal diameter of posterior uveal melanomas. Am J Ophthalmol. 2016;162:20-e1.

13 Busam KJ, Sung J, Wiesner T, von Deimling A, Jungbluth A. Combined BRAF(V600E)-positive melanocytic lesions with large epithelioid cells lacking BAP1 expression and conventional nevomelanocytes. Am J Surg Pathol. 2013;37(2):193-9.

14 Konstantinidis L, Roberts D, Errington RD, Kacperek A, Damato B. Whole anterior segment proton beam radiotherapy for diffuse iris melanoma. Br J Ophthalmol. 2013;97(4):471-4.

15 Willerding GD, Cordini D, Hackl C, Karle B, Lakotka N, Foerster MH, et al. Proton beam radiotherapy of diffuse iris melanoma in 54 patients. Br J Ophthalmol. 2015;99(6):812-6.

16 Leblanc A, Lumbroso-Le Rouic L, Desjardins L, Dendale R, Cassoux N. Diffuse iris melanoma: conservative treatment with proton beam therapy after limbal stem cell preservation or enucleation?. Ocul Oncol Pathol. 2019;5(6):396-401.

17 Finger PT, Tomar AS, Chin KJ. Palladium-103 plaque therapy for multifocal iris melanoma: Radiation of the entire anterior segment of the eye. Eur J Ophthalmol. April 2020:1120672120914235.

18 Brown D, Boniuk M, Font RL. Diffuse malignant melanoma of iris with metastases. Surv Ophthalmol. 1990; 34(5):357-64.

19 Rosenbaum PS, Boniuk M, Font RL. Diffuse uveal melanoma in a 5-year-old child. Am J Ophthalmol. 1988; 106(5):601-6.

20 Martin B. Diffuse malignant melanoma of the iris. Trans Ophthalmol Soc U K. 1973;93:473-5.

21 Font RL, Reynolds AM, Zimmerman LE. Diffuse malignant melanoma of the iris in the nevus of ota. Arch Ophthalmol. 1967;77(4):513-8.

22 Spencer WH, Iverson HA. Diffuse melanoma of the iris, with extrabulbar extension via the optic nerve. Surv Ophthalmol. 1965;10(4):365-71.

23 Luder P, Landolt E. [On a diffuse malignant melanoma of the iris]. Ophthalmologica. 1961;141(5):363-9.

24 Rones B, Zimmerman LE. The production of heterochromia and glaucoma by diffuse malignant melanoma of the iris. Trans Am Acad Ophthalmol Otolaryngol. 1957;61(4):447-63.

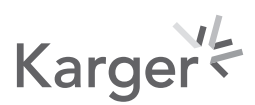


25 Richardson S. Diffuse malignant melanoma of iris; report of cases. Arch Ophthal. 1949;41(4):518-20.

26 Richardson S. Diffuse malignant melanoma of the iris. Report of two cases. Trans Am Ophthalmol Soc. 1947; 45:327-42.

27 Richardson S. Diffuse malignant melanoma of the iris; report of two cases. Am J Ophthalmol. 1948;31(10): 1223-31.

28 Greven CM, Stanton C, Yeatts RP, Shields CL. Diffuse iris melanoma in a young patient. Arch Ophthalmol. 1997; 115(5):682.

29 Kersten RC, Tse DT, Anderson R. Iris melanoma. Nevus or malignancy?. Surv Ophthalmol. 1985;29(6):423-33.

30 Skalicky SE, Giblin M, Conway RM. Diffuse iris melanoma: Report of a case with review of the literature. Clin Ophthalmol. 2007;1(3):339-42.

31 Singh AD, Dupps WJ, Biscotti CV, Suh JH, Lathrop KL, Nairn JP, et al. Limbal stem cell preservation during proton beam irradiation for diffuse iris melanoma. Cornea. 2017;36(1):119-22.

32 Petousis V, Finger PT, Milman T. Multifocal iris melanoma treated with total anterior segment palladium-103 plaque radiation therapy. Graefes Arch Clin Exp Ophthalmol. 2011;249(6):937-40. 